\title{
TITLE
}

\section{Applying Dignity of Risk principles to improve quality of life for vulnerable}

\section{persons}

Running head: Implementing Dignity of Risk in aged care

Key words: nursing home, residential aged care, quality of life, autonomy, decision-making Key points:

- Expressed through the 'Dignity of Risk' principle - allowing an individual the dignity afforded by risk-taking forms essential conditions for human dignity, enhanced quality of life, and the free development of the person

- Nursing home residents choices are often restricted by individuals directly responsible for making decisions on whether the choices are enacted

- Dignity of Risk is multifaceted and comprises of four elements: the person is at the centre of decision-making; life involves risk; individuals must have choice and control over decisions that impact on their life; and Dignity of Risk is a continuum of experiences

- To translate the multifaceted elements of Dignity of Risk into practice requires the aged care sector to develop unambiguous policies and guidelines about who will be responsible for the potential risks that may arise from residents' choices. Further, education programs directed specifically toward supporting care staff/management in the risk versus choice decisions for vulnerable nursing home residents are required.

Word count: 2,999 words

\section{Authors' names and affiliations}

Marta H. Woolford BHSc(Honours) ${ }^{1}$, Cassandra.de Lacy-Vawdon BHSc(Honours) ${ }^{2}$, Lyndal Bugeja $\mathrm{PhD}^{1}$, Carolina Weller $\mathrm{PhD}^{3}$, Joseph E. Ibrahim MBBS, PhD ${ }^{1}$

${ }^{1}$ Health Law \& Ageing Research Unit, Department of Forensic Medicine, Monash University School of Public Health \& Preventive Medicine, Melbourne, VIC 3006, Australia

${ }^{2}$ School of Public Health \& Preventive Medicine, Monash University, Melbourne, VIC 3004, Australia

${ }^{c}$ Monash Nursing and Midwifery Monash University, Clayton, VIC 3800, Australia

\section{Corresponding author}

Marta Woolford

Monash University, 65 Kavanagh Street

Southbank, Victoria 3006, Australia

E-mail: marta.woolford@monash.edu; Mobile: 0439853555

This is the author manuscript accepted for publication and has undergone full peer review but has not been through the copyediting, typesetting, pagination and proofreading process, which may lead to differences between this version and the Version of Record. Please cite this article as doi: $10.1002 /$ gps.5228

This article is protected by copyright. All rights reserved. 


\section{ABSTRACT}

OBJECTIVES: Freedom of choice impacts quality of life. Expressed through dignity of risk (DoR), nursing home $(\mathrm{NH})$ residents should be afforded the dignity to take risks to enhance well-being. How DoR is understood and implemented in the context of aged care remains largely unknown. This study explored the meaning; and the barriers and facilitators to applying DoR to NH residents.

METHODS: Qualitative study, comprising semi-structured interviews. Senior policy-makers and advocate guardians working in the aged care or disability-sector were invited to participate. Recruitment continued until data-saturation was reached. Two researchers coded interviews, applying inductive and thematic analysis.

RESULTS: Fourteen participants took part during 2016-17. Analysis demonstrated uniformity in participants' description of DoR, comprising four elements: (1)-individuals are at the centre of decision-making; (2)-life involves risk; (3)-individuals must have choice; and (4)-DoR is a continuum of experiences. Three main barriers for implementing DoR into practice were identified: (1)-balancing autonomy with risks; (2)-situational nature of DoR; and (3)-taking responsibility for risk.

CONCLUSION: The novel findings provide an explicit understanding of DoR and the facilitators and barriers to applying the principle in the $\mathrm{NH}$ setting. These findings inform those who engage in making and implementing choices in the presence of risk for vulnerable clients. To translate the multifaceted elements of DoR into practice requires the development of unambiguous policies/guidelines about who will be responsibility for potential risks that may arise from residents' choices. Further, education programs supporting care staff/management to enact resident choices in the presence of real or perceived risk are required. 


\section{INTRODUCTION}

The exercise of freedom of choice by vulnerable older people living in nursing homes (NHs) (Table-1) is central to their Quality of Life (QoL). Their autonomy is often systematically restricted by cognitive decline and physical limitations. ${ }^{1}$ Choices may be further restricted, or enhanced, by individuals who are directly responsible for making decisions on whether choices for $\mathrm{NH}$ residents are enacted.

Parallel with making some choices that enhance QoL is the increased risk of real or perceived physical harm. ${ }^{2}$ The notion that certain choices lead to possible harm is well recognised. ${ }^{2} \mathrm{~A} \mathrm{NH}$ decision-maker must balance potential risks of harm with potential benefits. These potential benefits may include perceptions of autonomy and personal control which are vital to health and well-being. ${ }^{2,3}$ Expressed through the 'Dignity of Risk' (DoR) principles (Table-1), to maintain a person's autonomy to make their own choices, individuals should be offered the dignity to take risks. ${ }^{2,3}$ This extends to $\mathrm{NH}$ residents, many of whom have deficits in their physical and cognitive capacity, which increases their risk of injury; and heightens care providers' urgency to apply risk minimising strategies. ${ }^{4,5}$

Aged care policy-makers and advocate guardians (Table-1) provide guidance and directions that affect the lives of people who cannot always make judgements about their own personal and lifestyle affairs. ${ }^{6}$ This often requires development of instructions and making decisions about how $\mathrm{NH}$ resident choices are negotiated and enacted in the presence of hazards which may lead to harm. ${ }^{6,7}$

The number of guardianship matters for vulnerable persons is increasing. ${ }^{6}$ It is predicted that the number of $\mathrm{NH}$ residents requiring support with decision-making will rise in parallel with

This article is protected by copyright. All rights reserved. 
increases in life expectancy and ageing populations. ${ }^{6,8}$ Aged care policy-makers and advocate guardians will continue to have a significant role in this area. ${ }^{6}$

How DoR is understood and implemented in the context of aged care remains largely unexplored. At present, two separate bodies of research dominate - one on 'dignity' ('choice') ${ }^{9-11}$ and another about ' risk' $^{12-14}$ The principles of DoR and the actions that potentially enhance QoL, require that the two concepts of risk and choice be studied together. The right to selfgovernance and the right of individuals to choose to take some risk in engaging in life experiences is undeniably a human rights issue that applies to people globally. Despite its international significance, cross-nationally, empirical studies into the meaning and application of DoR for NH residents are non-existent. Knowledge of DoR is a composite of commentary and opinion with largely speculative views being the only source for a definition of DoR and the application of the concept in the $\mathrm{NH}$ setting. ${ }^{15,16}$

The consequence is that decisions about a resident's lifestyle choice are paternalistic, risk-averse and largely dependent on the individual decision-maker, such as care staff. ${ }^{17}$ Residents deserve, and human rights demand, decision-making be transparent and evidence-based. ${ }^{18}$ Ensuring optimal QoL for older people requires policy-makers and advocate guardians to address the challenges of balancing support for residents' choices and mitigating the potential risks arising from those choices. To achieve this requires an explicit understanding of DoR and a framework to guide application. ${ }^{19-21}$

This study aimed to identify the components of DoR, and to identify the facilitators and barriers to applying DoR in the NH setting. This research is of relevance cross-nationally and aligns with contemporary western nations' government policy initiatives that highlight the need to facilitate independent living in older people. ${ }^{20,22-24}$ 


\section{METHODS}

This study was conducted in accordance with the consolidated criteria for reporting qualitative research (COREQ) guidelines ${ }^{25}$ (Supplementary Table-1).

\section{Design and Theory}

This qualitative design study applied interpretive phenomenology theory. Interpretive phenomenology research describes meanings attributed by individuals, addresses the personal lived experience, and guides examination of complex topics. ${ }^{26}$

\section{Setting}

The study was conducted in the state of Victoria, Australia's second most populous jurisdiction which, in 2016, had a population of approximately 6.2 million people. Victoria's population of adults aged over 65 years was 922,603 (15.6\% of the population), and there were approximately 47,624 NH places (year: 2016). ${ }^{27,28}$ In 2016, ${ }^{22}$ the annual federal and state government expenditure on aged care was $\$ 2.7$ billion (AUD), and 1,200 guardianship/advocacy services were being provided. ${ }^{6}$ The latter were required to make over 53,000 decisions for guardianship matters. ${ }^{6}$

\section{Recruitment Strategy}

Senior policy-makers and advocate guardians directly involved as substitute decision-makers, were invited to participate. Invitations were sent by one researcher (MHW) via email. Interviews were conducted by the same researcher (MHW) at participants' workplaces. Participants were purposively sampled and recruitment occurred in July and August-2016, and February-2017, and continued until data-saturation was reached. We included participants who had been employed in the aged care and/or disability sector for a minimum of two years, and had gained experience as either developing policy for advocate guardian decision-makers or working as advocate

This article is protected by copyright. All rights reserved. 
guardian decision-makers for persons who lacked decision-making capacity to make care or lifestyle decisions. Interviews were audio recorded and transcribed verbatim by MHW and a professional transcription service. No financial incentives or reimbursement were provided to participate.

\section{Researchers}

Researchers involved in the project were tertiary level educated; involved in health-care, geriatric medicine, nursing practice and research; and were unknown to the interviewee prior to the commencement of the study.

\section{Data Collection}

Demographic Characteristics

Demographic characteristics were collected from participants prior to the commencement of each interview (Table-2).

Interviews

Data were collected by individual in-depth, semi-structured face-to-face interviews. Interview questions were developed by primary author (MHW) in consultation with three senior researchers (JEI, LB, CW). Once developed, research questions were pilot tested for face-validity by a convenience sample of Victorian Institute of Forensic Medicine (VIFM), Health Law and Ageing Research Unit researchers $(n=3)$. Topics covered include exploring participants' familiarity/understanding of DoR, the words/phrases participants associate with DoR, and how DoR fits into the work they do (facilitators/barriers) (Supplementary Table-2:Interview questions).

\section{Data Analysis}

Descriptive statistical techniques were performed to examine participant characteristics. Thematic analysis was performed on the transcripts simultaneously by two researchers (MHW 
and $(\mathrm{d}-\mathrm{V})$. Discrepancies in coding were discussed and resolved by consensus. Coding was done inductively whereby themes were reviewed and developed with the addition of new data.

\section{Reflexivity}

To minimise the influence of researchers' assumptions and preconceptions on research outcomes, reflexivity was applied throughout the entire research process. This included the development and application of an explicit interview guide; engagement of a professional transcription service to transcribe verbatim audio recorded interviews; discussion of interview experiences among research team; data analysis performed simultaneously by two researchers ( $\mathrm{MHW}$ and $\mathrm{Cd}-\mathrm{V}$ ) with discrepancies in coding and subjective reflections discussed and resolved by consensus; and including a multi-disciplinary team in the write-up of results, thereby minimising the subjective interpretations that may arise with one author.

\section{Ethics}

The study was approved by the VIFM Research Advisory Committee (RAC 016/16); and the Department of Health and Human Services-Centre for Research and Evaluation-State Government Victoria, Australia (ADD/16/17807). A 'participant information sheet' was provided containing description of project, written informed consent was obtained before commencing interviews.

\section{RESULTS}

\section{Participants and Data Saturation}

Fourteen participants were invited and interviewed individually. Each interview lasted 45-60 minutes. The assessment for data saturation was conducted in two stages. The initial assessment, an interim analysis of the first seven interviews, showed themes emerging but data saturation had not been reached. ${ }^{29}$ A further seven interviews were conducted after which data

This article is protected by copyright. All rights reserved. 
analysis confirmed no new themes. ${ }^{29}$ The point of data saturation had been reached and researchers were confident additional interviews would not identify new major themes. ${ }^{29}$ Of the 14 participants a greater number were female $(n=9)$, and aged $50-59$ years $(n=6)$. All participants were tertiary qualified and nine held senior managerial roles. Participants' experience in their current role ranged from 2 to 30 years (median 13.5 years; Interquartile Range 7-24 years). Ten participants had ongoing direct client contact as advocate guardian decision-makers during their regular work (range 1-20 clients per-month) (Table-2). The four participants without direct client contact were involved in developing policy within their management roles.

\section{Components of DoR}

Analysis demonstrated uniformity in the components of DoR. Participants with and without direct client contact reported the DoR principles included four main themes: (1) the client is at the centre of decision-making; (2) life involves risk; (3) clients must have choice and control over decisions that impact on their life; and (4) DoR is a continuum of experiences.

\section{Theme-1: The Client is at the Centre of Decision-Making}

All participants described DoR as the notion that clients should receive and participate in care, treatment, and activities that respects their values. This notion was highlighted as particularly important in the context of substitute and support decision-makers who act in the role of clients lacking decisional capacity. Participants described the importance of putting the client's values at the centre of decision-making in situations where the decision has direct influence on a client's self-perceived QoL and on the way the client experiences life (Table-3;Quote-A).

All participants described the meaning of DoR as relating to human rights. Conversations comprised of 'rights-based' language with participants using terms such as: 'right to make 
decisions', 'right to control', and 'right to dignity'. Discourse relating to 'rights' was strongly focused on the individual, whilst references to organisational rights were absent.

\section{Theme-2: Taking Risks -Life Brings with it Risk}

All participants described 'taking risks' as related to the DoR principles, with all participants describing this risk is an important part of life (Table-3; Quote-B).

All participants reported implementing DoR into practice required an acceptance that clients will want to take risks in daily life. This was especially important for vulnerable populations who require decision-making support about a range of activities of daily living, including recreational activities, accommodation and care choices.

When discussing risk all participants relayed this term as having a negative meaning and adverse consequences. In particular, physical injury was emphasised as a major risk. Participants nevertheless described living a life that includes risk as being essential to maintaining a life that accords with a client's values; emphasising any attempt to implement risk averse strategies may impact on a client's wellbeing.

\section{Theme-3: Choice and Control Over Decisions}

The third major theme emerging from participants' explanation of the DoR principles related to clients having choice and control over decisions that impact on their life. Participants' emphasised choice is important when applying DoR due to the independence and sense of control choice provides (Table-3; Quote-C).

One participant (P10), described DoR as facilitating and enabling people to do the things they would like to do but were not able to do independently:

This article is protected by copyright. All rights reserved. 
"It's enabling choice for somebody who might have difficulty obtaining that choice. If you're in a wheelchair for instance, to enable you to do the things that you want to do even though you're in the wheelchair, is important" (P10).

\section{Theme-4: DoR is a Continuum of Experiences}

All participants described DoR as a continuum of experiences, rather than 'an event'. In describing DoR, participants used the term 'life', with terms such as 'event' absent from participants' explanations. For participants, the process of risk-taking, making choices and having control revolved around the individual person throughout their life (Table-3; Quote-D).

\section{Translation of DoR into Practice}

When discussion in the interviews moved away from describing DoR and towards implementing the concept into practice, participants' responses highlighted a disconnection between the theory (how participants describe DoR) and practice (how participants implement DoR in their work) (Table-3;Quote-E).

When participants were asked to describe DoR their explanations related to four elements: the person, taking risks, choice, and the process. In contrast, when participants were asked how the principles translated into practice the language around DoR changed to focus almost solely on risk. In particular, how to minimise and quantify the real or perceived negative risks that may cause physical injury. For all participants 'risk' was at the centre of their view when implementing DoR decisions (Table-3; Quote-F \& G).

Analysis of the interviews identified three influencing factors that served as barriers for the implementation of DoR into practice, including: (1) the need to balance autonomy with risks; (2) 
the situational nature of DoR; and (3) the need to take responsibility for, or to transfer, risk. These are explained individually below.

\section{Influencing Factors: Major-Themes}

\section{Balance of Autonomy with Risks}

All participants described their need to continuously balance risk with autonomy. This results in DoR becoming two mutually exclusive ideas: (1) serious risk resulting in placing limitations on an individual, and (2) choice which results in supporting autonomy (Table-3;Quote-H).

Participants described their decisions to choose between risks, and whether they could be managed, or autonomy, as being influenced by multiple factors. These include: overall health status of their client, availability of support services, study participant 'comfort' with the potential risk, and the perceived or real severity of the risk that is to be taken. Participants further articulated the decision-making process was complex and unique for each client (Table3;Quote-I).

The Situational Nature of DoR

All participants described examples of unacceptable application of DoR in practice. The explanations varied (Table-4), however the most frequently reported was for persons with dementia (PWD). Participants spoke of PWD as being vulnerable to injury and enacting certain DoR activities was only reasonable under specific conditions, including: adequate staffing levels, qualified staff, minimising impact on others, feasibility (time/cost), completion of physical safety assessments, and the activity must be pre-arranged.

The Need to Take Responsibility For, or to Transfer, Risk 
Participants described implementing DoR into practice as requiring someone to be prepared to take responsibility for the adverse outcome from taking the risk that may follow a DoR decision. Particularly for participants with direct client contact, assigning responsibility for potential risks was seen as crucial for the implementation of DoR in practice (Table-3;Quote-J, K,L).

Overall, study participants varied on the degree of professional risk they were willing to accept. Participants described they were prepared to accept a higher degree of risk if the client had appropriate support from carers and/or services.

Across the interviews there was discussion by participants about the potential need to 'transfer' responsibility for the risk onto others (within or outside of their workplace). This was described as important at times when the participant was not prepared to take responsibility for the perceived or real risks. Participants suggested this transfer of risk may be directed towards managers, executive teams, legal advice, external services, or the client. Participants described applying DoR in practice as not possible when individuals or organisations were not prepared to take accountability for the risks associated with the decision.

\section{Additional Barriers and Facilitators to applying DoR: Minor-Themes}

Participants described additional barriers and facilitators to implementing DoR principles in the workplace. These are presented in Figure 1 and identify the individual, organisational, and industry level barriers and facilitators.

\section{DISCUSSION}

Senior policy-makers and advocate guardians described DoR as constituting four interrelated components: the person, taking-risks, choice, and the process. Participants' explanations of DoR is consistent with person-centred care in which a client's choices and values are considered a 
necessary part of care to support autonomy and meaning in life. ${ }^{30}$ The exception is the participants' inclusion of the important role risk has in daily life for older vulnerable persons. Recognising vulnerable clients make choices that involve risk, often termed 'positive risk-taking', is instrumental for those persons with cognitive and physical disabilities to manage their health and its effects. This approach supports independent living and provides the opportunity to construct their lives in accordance with their values. ${ }^{31-33}$

Inconsistencies were observed between participants' description of DoR and application of the concept in practice. Participants' responses on the application of DoR in practice overwhelmingly focused on potential for harm, in particular, quantifying the real or perceived risks that may cause physical injury. Directly comparing our findings with other empirical research is not possible as insights into DoR are limited to educational resources and speculative commentaries. ${ }^{2,16}$ Our findings are, however, comparable to research examining independence versus safety in older PWD. ${ }^{30,34-37}$ These earlier publications report care professionals have high alertness to risk in practice resulting in the prioritisation of the reduction of risk rather than the promotion of independence.

Our findings may, in part, be explained by the vulnerability of the clients and the study participants' professional responsibilities. The clients are particularly vulnerable to increased risk of injury and death due to inevitable physical and cognitive decline; and age-related disease such as dementia. ${ }^{38}$

However, our findings also suggest the negative symbolic meaning ascribed to risk influences DoR decisions towards physical safety and protection. ${ }^{17}$ In the present study, the meaning of risk ascribed by participants was without exception negative and linked to physical injury. Future 
research must focus on how clients' choices that involve risk can be negotiated and recognised as having potentially beneficial outcomes, such as enhanced mood and improved self-esteem. ${ }^{33}$

An important finding of the present study is the situational nature of DoR for participants which led to explicitly limiting the application of the principles in daily practice. Participants commonly stated it is unreasonable to apply DoR principles for clients with cognitive impairment as this population was perceived to be particularly vulnerable to risk. Whilst individuals vary significantly in their cognitive abilities, for most independence and self-efficacy continues to have a positive influence on perceived QoL. ${ }^{39}$ Our findings highlight the need to identify the nature of the support care providers need to enable choices, in the presence of risk, among clients with an impairment. Our findings, and those from earlier publications, suggest understanding client values, ${ }^{40}$ effective use of technology, ${ }^{41}$ and support from management with clear processes ${ }^{30}$ may provide this support.

Limitations of this study include the qualitative nature which places responsibility for judging the applicability of the findings to local settings with the reader. ${ }^{42}$ The presence of social desirability bias in which participants focus on issues that put their application of DoR principles in a more positive light. Further limitation is the absence of voice of persons working and living in the $\mathrm{NH}$ setting. Exploring the perspectives of residents and carers will play a valuable role in reflecting their values, understanding the lived experience, and provide knowledge and experience about what is truly important to them. Future research addressing this limitation will compliment findings from the present study and ultimately support the application of DoR principles into practice.

Strengths of the study include participants who are in positions of complex decision-making for vulnerable clients and the novel examination of client's choices that involve potential risks. 
Previous studies largely focus on either dignity or person-centered care, ${ }^{9-11}$ or riskmanagement. ${ }^{16}$ Another strength is the independent review of content by two researchers, and reaching data saturation.

The results from this study inform those who engage in making-decisions for vulnerable clients. Models of care that are supportive of balancing choices and risks in practice are few. Change to promote a better understanding and the actions to implement a person's choices require a common understanding which is promoted by the presence of an explicit definition and a guiding framework. The components of DoR identified by participants' forms a foundation on which to develop a practice framework. Further, the identified barriers and facilitators to implementation will enable better focusing organisational resources.

\section{CONCLUSION}

Given the prominent attention choice and independent living by older people receives from health and social science literature, ${ }^{43}$ and western nations governments', ${ }^{20,22-24}$ the findings of this study are timely and a novel contribution. The findings provide new information for expanding the public discourse about how choices for vulnerable older persons can be enacted in the presence of risk.

\section{DECLARATION OF INTEREST}

Conflicts of interest: none.

\section{DECLARATION OF SOURCES OF FUNDING}

This research did not receive any specific grant from funding agencies in the public, commercial, or not-for-profit sectors. MHW is a PhD student supported by an Australian Government

This article is protected by copyright. All rights reserved. 
Research Training Program Scholarship. The funders did not contribute nor influence the findings or conclusions.

\section{ACKNOWLEDGEMENTS}

The authors acknowledge the contribution Aged Care Consumer Advocate Belinda Evans for her generosity in critiquing the final draft.

\section{DATA AVAILABILITY}

The data that support the findings of this study are available on request from the corresponding author. The data are not publicly available because of privacy or ethical restrictions.

This article is protected by copyright. All rights reserved. 


\section{REFERENCES}

1. Hennessy $\mathrm{CH}$. Autonomy and risk: the role of client wishes in community-based long-term care. Gerontologist. 1989; 29(5):633-639.

2. Ibrahim JE, Davis MC. Impediments to applying the 'dignity of risk' principle in residential aged care services. Australasian J Ageing. 2013; 32(3):188-193.

3. Perske R. The dignity of risk and the mentally retarded. Mental retardation. 1972; 10(1):24-27.

4. Bono C, Henry B. A positive risk approach when clients choose to live at risk: A palliative care discussion. Ethics support palliat care. 2016; 10:1-6.

5. Forbes-Thompson RS, Leiker RT, Bleich RM. High-performing and low-performing nursing homes: A view from complexity science. Health Care Manag Rev. 2007; 32(4):341-351.

6. Office of the Public Advocate. Growing Complexity in Guardianship: Trends in the Advocate Guardian Program, Office of the Public Advocate, Victoria. In. Victoria, Australia: Office of the Public Advocate; 2016:1-30.

7. Australian Government Department of Health. Ageing and Aged Care; 2018. Available at: https://agedcare.health.gov.au/publications-and-articles/legislation. (Accessed 26 January 2018).

8. Dreyer A, Forde R, Nortvedt P. Autonomy at the end of life: life-prolonging treatment in nursing homes-relatives' role in the decision-making process. J Medical Ethics. 2009; 35(11):672-677.

9. McSherry W. Dignity in care: meanings, myths and the reality of making it work in practice. Nurs times. 2010; 106(40):20-23.

10. Gallagher A, Li S, Wainwright $P$, et al. Dignity in the care of older people - a review of the theoretical and empirical literature. BMC Nursing. 2008; 7(1):11.

11. Cairns $D$, Williams $V$, Victor $C$, et al. The meaning and importance of dignified care: findings from a survey of health and social care professionals. BMC Geriatrics. 2013; 13(1):28.

12. Godin P. 'You don't tick boxes on a form': A study of how community mental health nurses assess and manage risk. Health, Risk \& Soc. 2004; 6(4):347-360.

13. M Lewis, Noyes J. Risk management and clinical governance for complex home-based healthcare. Paed Nurs. 2007; 19(6):23-28.

14. Titterton M. Risk and risk taking in health and social welfare. London: Jessica Kingsley Publishers; 2005.

15. Ibrahim J, Davis M. Impedimens to applying the 'Dignity of Risk' principle in residential aged care services. Australasian J Ageing. 2013; 32(3):188-193.

16. Nay R. The dignity of risk. Aust Nurs J. 2002; 9(9):33.

17. Kasperson RE, Renn $O$, Slovic $P$, et al. The Social Amplification of Risk: A Conceptual Framework. Risk Analysis. 1988; 8(2):177-187.

18. United Nations. Universal Declaration of Human Rights: reprint of United Nations General Assembly Resolution, 1948. JAMA. 1998; 280:469.

19. Australian Government. Aged Care: The aged care system; 2018. Available at: https://www.alrc.gov.au/publications/aged-care-system. (Accessed 26 January 2018).

20. Australian Government. Patient-centred care: Improving quality and safety by focusing care on patients and consumers; 2012. Available at: https://www.safetyandquality.gov.au/wpcontent/uploads/2012/01/PCCC-DiscussPaper.pdf. (Accessed 15 February 2018).

21. Sikma SK, Young HM. Balancing freedom with risks: the experience of nursing task delegation in community-based residential care settings. Nursing Outlook. 2001; 49(4):193-201.

22. Australian Institute of Health and Welfare. Residential aged care in Australia 2010-2011: A statistical overview. Edited by AlHW, vol. 68. Canberra, Australia: AlHW 2012.

23. Centers for Disease Control and Prevention. Long-Term Care Providers and Services Users in the United States: Data From the National Study of Long-Term Care Providers 2013-2014. Edited by CDC, vol. 38: CDC: National Center for Health Statistics 2016:1-108.

24. Office of National Statistics. Changes in the Older Resident Care Home Population between 2001 and 2011. UK: Office of National Statistics 2014:1-10. 
25. Tong. A, Sainsbury. P, Craig. J. Consolidated criteria for reporting qualitative research (COREQ): a 32item checklist for interviews and focus groups. Int J Quality Health Care. 2007; 19(6):349-357.

26. Smith JA, Osborn M. Interpretative phenomenological analysis as a useful methodology for research on the lived experience of pain. British J Pain. 2015; 9(1):41-42.

27. Australian Bureau of Statistics. Population by Age and Sex, Regions of Australia; 2016. Accessed at: http://www.abs.gov.au/ausstats/abs@.nsf/Latestproducts/3235.0Main\%20Features252016?opendo cument\&tabname=Summary\&prodno=3235.0\&issue=2016\&num=\&view. (Accessed 10 February 2018).

28. Department of Health: Australian Government. Aged care services - Report on Government Services 2017: Chapter 14. Department of Health; 2017:1-181.

29. Fusch P, Ness L. Are We There Yet? Data Saturation in Qualitative Research. The Qual Report. 2015; 20(9):1408-1416.

30. Rosemond AC, Hanson CL, Ennett TS, et al. Implementing person-centered care in nursing homes. Health Care Manag Rev. 2012; 37(3):257-266.

31. Spilsbury K, Hewitt C, Stirk L, et al. The relationship between nurse staffing and quality of care in nursing homes: A systematic review. Int J Nurs Studies. 2011; 48(6):732-750.

32. Boggatz T. Quality of life in old age - a concept analysis. Int J Older People Nurs. 2015; 11(1):55-69.

33 Brett J, Moran A, Green G, et al. Managing risk in community services a preliminary study of the impacts of risk management on victorian services and clients. Australia: Melbourne: LaTrobe University; 2009:1-146.

34. Lawrence V, Murray J. Balancing independence and safety: the challenge of supporting older people with dementia and sight loss. Age and Ageing. 2010; 39(4):476-480.

35. Donnelly L, Macentee M. Care Perceptions among Residents of LTC Facilities Purporting to Offer Person-Centred Care. Canadian J Aging / La Revue canadienne du vieillissement. 2016; 35(2):149160.

36. Speller B, Stolee P. Client safety in assisted living: perspectives from clients, personal support workers and administrative staff in Toronto, Canada. Health \& Social Care Comm. 2015; 23(2):131140.

37. Clemens EL, Hayes HE. Assessing and balancing elder risk, safety and autonomy: decision-making practices of health care professionals. Home Health Care Services Quart. 1997; 16(3):3-20.

38. Alzheimer's \& Dementia. Alzheimer's disease facts and figures: Alzheimer's Association Report. Alzheimer's \& Dementia: J Alzheimer's Assoc 2018;14:367-429.

39. Farina N, Page T, Daley $S$, et al. Factors associated with the quality of life of family carers of people with dementia: A systematic review.(Report). Alzheimer's \& Dementia: J Alzheimer's Assoc. 2017; 13(5):572-581.

40. Eales J, Keating N, Damsma A. Seniors' experiences of client-centred residential care. Ageing and Society. 2001; 21(3):279-296.

41. Moulton M, Rittenhouse D. Honoring the balance of independence versus safety for persons with dementia: Using wearable tech to address wandering behavior. Alzheimer's \& Dementia. 2015; 11:189-190.

42. Graham F, Sinnott K, Snell DL, et al. A more "normal" life: Residents', family, staff, and managers' experience of active support at a residential facility for people with physical and intellectual impairments. J Intellectual and Develop Disability. 2013; 38(3):256-264.

43. Slater L. Person-centredness: A concept analysis. Contem Nurse. 2006; 23(1):135-144.

44. World Health Orgnization. Health Policy. Avilable at: http://www.who.int/topics/health policy/en/. (Accessed 10 February 2018). 
Table 1 Definitions of key terms

Term

Definition

\begin{tabular}{ll}
\hline Nursing home & $\begin{array}{l}\text { A business that provides personal care and nursing care, together with } \\
\text { accommodation, to older people in need of care and accommodation. }\end{array}$ \\
\hline Nursing home resident & $\begin{array}{l}\text { A person who lives in a nursing home either temporarily (respite care) or } \\
\text { permanently. }\end{array}$ \\
\hline Dignity of Risk & $\begin{array}{l}\text { Dignity of risk is the principle of allowing an individual the dignity afforded } \\
\text { by risk-taking, with subsequent enhancement of personal growth and }\end{array}$ \\
& quality of life ${ }^{15}$ \\
\hline Policy-makers & $\begin{array}{l}\text { Individuals involved in making decisions, plans, and actions to achieve } \\
\text { specific health care goals within a society }\end{array}$ \\
\hline Advocate guardian & $\begin{array}{l}\text { A person appointed by a tribunal to make personal, lifestyle and medical } \\
\text { decisions for people who do not have decision-making capacity to make } \\
\left.\text { their own decisions }{ }^{6}\right]\end{array}$
\end{tabular}

This article is protected by copyright. All rights reserved. 
Table 2 Participant demographic and professional profile

\begin{tabular}{|c|c|c|c|c|c|c|}
\hline $\begin{array}{l}\text { Interview } \\
\text { number }\end{array}$ & $\begin{array}{l}\text { Age } \\
\text { group }\end{array}$ & $\begin{array}{c}\text { Tertiary } \\
\text { qualifications }\end{array}$ & $\begin{array}{l}\text { Experience in } \\
\text { current job } \\
\text { (years) }\end{array}$ & $\begin{array}{l}\text { Client } \\
\text { contact }\end{array}$ & $\begin{array}{c}\text { Number of clients } \\
\text { per month }\end{array}$ & Main client* group \\
\hline P 1 & $50-59$ & Yes & 28 & Yes & 3 & CCR \\
\hline P 2 & $30-29$ & Yes & 3 & Yes & $15-20$ & NHR \\
\hline P 3 & $50-59$ & Yes & 18 & No & 0 & - \\
\hline P 4 & $60+$ & Yes & 14 & Yes & 1 & CCR \\
\hline P 5 & $50-59$ & Yes & 26 & Yes & 6 & NHR \\
\hline P 6 & $30-39$ & Yes & 10 & Yes & 3 & NHR, CCR, RDS \\
\hline P 7 & $50-59$ & Yes: & 5 & Yes & 20 & NHR, CCR, RDS \\
\hline P 8 & $30-39$ & Yes & 6 & No & 0 & NHR \\
\hline P 9 & $50-59$ & Yes & 1.5 & Yes & 15 & RDS \\
\hline P 10 & $60+$ & Yes & 10 & Yes & 1 & RDS \\
\hline P 11 & $50-59$ & Yes & 5.5 & Yes & 15 & RDS \\
\hline P 12 & $60+$ & Yes & 13 & No & 0 & NHR \\
\hline P 13 & $40-49$ & Yes & 15 & No & 0 & RDS \\
\hline P 14 & $50-59$ & Yes & 29 & Yes & 5 & RDS \\
\hline
\end{tabular}

Ledger: $\left({ }^{*}\right)$ Client includes recipients of disability services (RDS), Nursing home residents (NHR), or community care recipients (CCR) Note: Additional characteristics collected from study participants include: gender, age group, tertiary qualifications, job title, and core duties in current workplace

This article is protected by copyright. All rights reserved. 
Table 3 Themes identified and examples from participant interviews

\begin{tabular}{|c|c|c|}
\hline Quote & Theme & Quote example \\
\hline A & $\begin{array}{l}\text { The client is at the centre of decision- } \\
\text { making }\end{array}$ & $\begin{array}{l}\text { "(DoR is about)...being able to live in a dignified way that accords with your own sense of what living a } \\
\text { decent life is" (P3: pOdcc). }\end{array}$ \\
\hline B & Taking risks - Life brings with it risk & $\begin{array}{l}\text { "So it's (DoR) recognising ... we all have risks in our lives and we all walk out every day and we can't, I } \\
\text { don't think we can avoid risk" (P4: pWdcc). }\end{array}$ \\
\hline C & Choice and control over decisions & "It's a sense of control isn't it, that everyone has the right to have that, at some level" (P14: pWdcc). \\
\hline D & Continuum of experiences & $\begin{array}{l}\text { "...the continuum experience - that I think is at the heart of what DoR is... in some ways it's more } \\
\text { important to make the choices about how to live rather than how to die" (P3: POdcc). }\end{array}$ \\
\hline E & Translation of DoR into practice & $\begin{array}{l}\text { "So, it's a bit of a tricky one because I think the issue with DoR is often the ethos or the stated principle } \\
\text { doesn't often match the reality of what happens" (P2: pWdcc). }\end{array}$ \\
\hline $\mathbf{F}$ & Translation of DoR into practice & $\begin{array}{l}\text { "We should be giving them (the clients) as much freedom as is possible without them (the clients) } \\
\text { being at risk" (P7: pWdcc). }\end{array}$ \\
\hline G & Translation of DoR into practice & $\begin{array}{l}\text { "Sometimes it seems like they (carers) may not analyse whether it is an acceptable level of risk or not, } \\
\text { that it is just perceived that there is risk" (P6: pWdcc). }\end{array}$ \\
\hline $\mathbf{H}$ & Balance of autonomy with risk & "I want you to be really clear about at what point the risk outweighs the benefit" (P3: pOdcc) \\
\hline $\mathbf{I}$ & Balance of autonomy with risk & $\begin{array}{l}\text { "Looking at the person's best interests ... we have to take into consideration what their wishes are, we } \\
\text { also have to look at what risks there will be, we have to look at our principles of looking at how we go } \\
\text { about making sure that we are stepping into their shoes and making a decision that is reasonable and } \\
\text { based on all the information that we have" (P4: pWdcc). }\end{array}$ \\
\hline J & Professional risk accountability & $\begin{array}{l}\text { "Now when you're telling them (NH carers) that we need to respect people's DoR that involves them } \\
\text { taking on some risk professionally, to give an older person a degree of risk, if something goes wrong } \\
\text { they (carers) are taking on that risk" (P2: pWdcc). }\end{array}$ \\
\hline K & Professional risk accountability & $\begin{array}{l}\text { "And they (the hospital) ended up changing their view and basically said if I was prepared to accept the } \\
\text { risk and make that decision they would look to implement the maximum services that they could" (P5: } \\
\text { PWdcc). }\end{array}$ \\
\hline $\mathbf{L}$ & Organisational risk accountability & $\begin{array}{l}\text { "Nevertheless, what guides the decision-making is, more often than not, very much loaded around } \\
\text { what might be seen to be an organisational risk." (P11: PWdcc). }\end{array}$ \\
\hline
\end{tabular}

Ledger: (pOdcc) Participant without direct client contact; (pWdc) Participant with direct client contact

This article is protected by copyright. All rights reserved. 
Table 4 DoR is situational: Influencing factors and examples from participant interviews

\begin{tabular}{|c|c|c|}
\hline & Influencing factor & Example \\
\hline \multirow{4}{*}{ 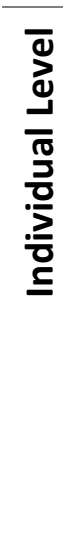 } & $\begin{array}{l}\text { Cognitive ability and individual } \\
\text { capacity }\end{array}$ & $\begin{array}{l}\text { "Certainly with dementia you have to take a whole lot of other things into account"(P12) } \\
\text { "So I think that goes partially some way [to] recognising that maybe we need more procedures, protocols, control } \\
\text { over one group than the other" (P2) }\end{array}$ \\
\hline & Stage of life & $\begin{array}{l}\text { "So as responsible adults we say we understand that certain stages in life will restrict choice if people aren't in a } \\
\text { position to exercise some kind of judgement that would avert harm. So, I don't think it's an all or nothing (thing)" } \\
\text { (P1) }\end{array}$ \\
\hline & Different needs & $\begin{array}{l}\text { "But the other thing you introduce is that there are the issues that surround the patient. But there are also the } \\
\text { issues that implicate the feelings of the health care provider or the family member who are in a position, allegedly } \\
\text { in a position of decision making" (P1: PWdcc) } \\
\text { "At the end of the day you're not going to satisfy everyone, but if you can demonstrate that you have weighed up } \\
\text { the risks, that you have provided the information" (P12) }\end{array}$ \\
\hline & Based on physical safety & "...it's about that person's safety" (P5) \\
\hline \multirow{8}{*}{ 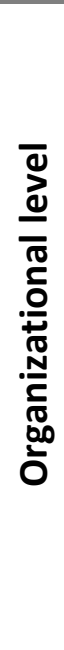 } & $\begin{array}{l}\text { The participant has the required } \\
\text { support; is prepared }\end{array}$ & $\begin{array}{l}\text { "I know that if the other person was not there (then) there's not adequate support ... (to) support him, at least there } \\
\text { is monitoring by this other person, and would be the breaking point if she had to go" (P4) }\end{array}$ \\
\hline & Quality of staff and staffing levels & $\begin{array}{l}\text { "And so the policies around outdoor time is going to have to be factoring this person's ability to make a good decision, } \\
\text { the effect that this seems to have on their overall wellbeing at the availability of supervision" (P1) }\end{array}$ \\
\hline & Risk must be supervised & $\begin{array}{l}\text { "I felt that in a supervised environment in the NH and with the appropriate support around her that that was } \\
\text { something she should be able to do" (P6) }\end{array}$ \\
\hline & Risk must be pre-arranged & $\begin{array}{l}\text { "So it's always ... saying okay we just have to be prepared and have a backup plan for if the situation breaks down" } \\
\text { (P4) }\end{array}$ \\
\hline & Resources & "There's a lot required of the staff to enable that" (P10) \\
\hline & Impact on others & $\begin{array}{l}\text { "We do allow residents to do that (drinking and smoking) up until the point it interferes with a provision of care to } \\
\text { them or impacts other residents" (P2) }\end{array}$ \\
\hline & $\begin{array}{l}\text { Fits into an acceptable safety } \\
\text { framework }\end{array}$ & $\begin{array}{l}\text { "A lot of what we do, we do through a Risk Management Framework and that's really around the greatest risks to } \\
\text { residents and ultimately exposure to the service and the Department occur around clinical care areas" (P8) }\end{array}$ \\
\hline & $\begin{array}{l}\text { Assessment of return of } \\
\text { investment versus risk }\end{array}$ & $\begin{array}{l}\text { "As people's health and needs deteriorate, you might have to impose more restrictive interventions for that person's } \\
\text { safety" (P13) }\end{array}$ \\
\hline
\end{tabular}

This article is protected by copyright. All rights reserved. 


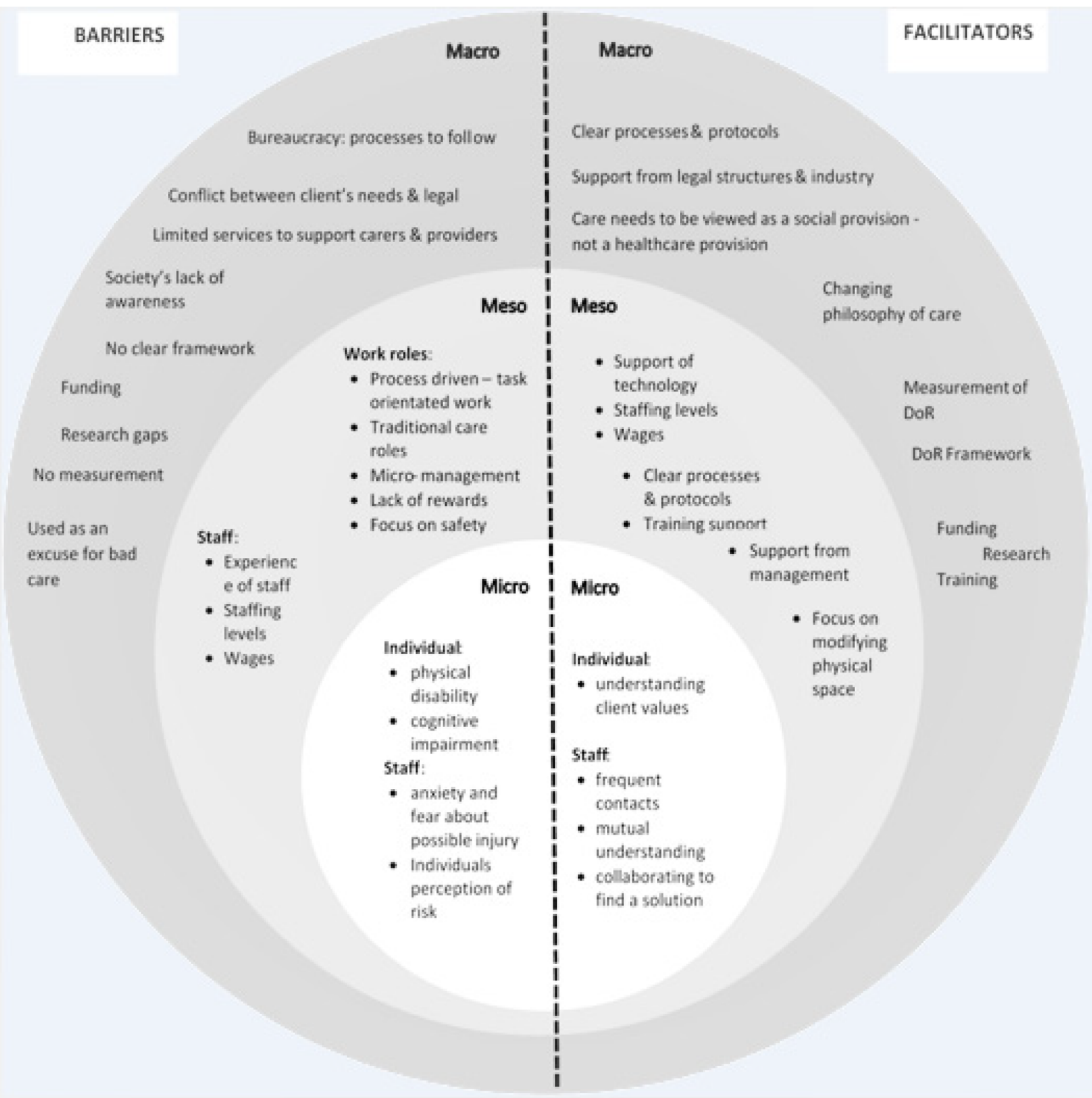

Figure 1_v_edited.v.300TIFF.tif 


\section{University Library}

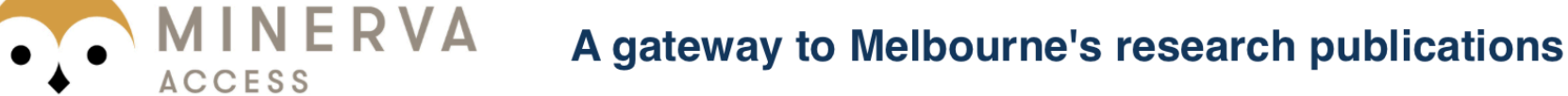

Minerva Access is the Institutional Repository of The University of Melbourne

Author/s:

Woolford, MH;de Lacy-Vawdon, C;Bugeja, L;Weller, C;Ibrahim, JE

Title:

Applying dignity of risk principles to improve quality of life for vulnerable persons.

Date:

2020-01

Citation:

Woolford, M. H., de Lacy-Vawdon, C., Bugeja, L., Weller, C. \& Ibrahim, J. E. (2020). Applying dignity of risk principles to improve quality of life for vulnerable persons.. Int J Geriatr Psychiatry, 35 (1), pp.122-130. https://doi.org/10.1002/gps.5228.

Persistent Link:

http://hdl.handle.net/11343/286543 